\title{
Molecular epidemiology of Avian Rotaviruses Group A and D shed by different bird species in Nigeria
}

\author{
Maude Pauly ${ }^{1 *+}$ (D), Oluwole O. Oni ${ }^{2+}$, Aurélie Sausy ${ }^{1}$, Ademola A. Owoade ${ }^{3}$, Christopher A. O. Adeyefa ${ }^{3}$,
} Claude P. Muller ${ }^{1}$, Judith M. Hübschen ${ }^{1}$ and Chantal J. Snoeck ${ }^{1}$

\begin{abstract}
Background: Avian rotaviruses (RVs) cause gastrointestinal diseases of birds worldwide. However, prevalence, diversity, epidemiology and phylogeny of RVs remain largely under-investigated in Africa.

Methods: Fecal samples from 349 birds (158 symptomatic, 107 asymptomatic and 84 birds without recorded health status) were screened by reverse transcription PCR to detect RV groups A and D (RVA and RVD). Partial gene sequences of VP4, VP6, VP7 and NSP4 for RVA, and of VP6 and VP7 for RVD were obtained and analyzed to infer phylogenetic relationship. Fisher's exact test and logistic regression were applied to identify factors potentially influencing virus shedding in chickens.

Results: A high prevalence of RVA (36.1\%; 126/349) and RVD (31.8\%; 111/349) shedding was revealed in birds. In chickens, RV shedding was age-dependent and highest RVD shedding rates were found in commercial farms. No negative health effect could be shown, and RVA and RVD shedding was significantly more likely in asymptomatic chickens: RVA/RVD were detected in $51.9 / 48.1 \%$ of the asymptomatic chickens, compared to $18.9 / 29.7 \%$ of the symptomatic chickens $(p<0.001 / p=0.01)$. First RVA sequences were obtained from mallard ducks (Anas platyrhynchos) and guinea fowls (Numida meleagris). Phylogenetic analyses illustrated the high genetic diversity of RVA and RVD in Nigerian birds and suggested cross-species transmission of RVA, especially at live bird markets. Indeed, RVA strains highly similar to a recently published fox rotavirus (RVA/Fox-tc/ITA/288356/2011/G18P[17]) and distantly related to other avian RVs were detected in different bird species, including pigeons, ducks, guinea fowls, quails and chickens.
\end{abstract}

Conclusion: This study provides new insights into epidemiology, diversity and classification of avian RVA and RVD in Nigeria. We show that cross-species transmission of host permissive RV strains occurs when different bird species are mixed.

Keywords: Avian rotaviruses, Host permissiveness, Virus diversity, Epidemiology, Sub-Saharan Africa

\section{Background}

Rotavirus (RV) infections are highly prevalent worldwide [1] and cause gastroenteritis mainly in infants [2] and young animals (reviewed in [3]). Different bird species are susceptible to RV infections ([4]; reviewed in [5]). Although avian RVs are involved in

\footnotetext{
* Correspondence: Maude.Pauly@lih.lu

${ }^{\dagger}$ Equal contributors

'Infectious Diseases Research Unit, Department of Infection and Immunity, Luxembourg Institute of Health, 29 rue Henri Koch, L-4354 Esch-sur-Alzette, Luxembourg

Full list of author information is available at the end of the article
}

the pathogenesis of the runting-stunting syndrome of broiler chicks [6], RV shedding from asymptomatic birds has also been reported [7].

The genome of these non-enveloped, double-stranded RNA viruses is composed of 11 segments, encoding six viral structural proteins (VP1 to VP4, VP6, and VP7) and five to six nonstructural proteins (NSP1 to NSP5/ NSP6). Eight RV groups A to H (RVA-RVH) are defined by the International Committee on Taxonomy of Viruses (ICTV) based mainly on group-specific antigenicity of VP6 (reviewed in [8]). In addition, a percentage cut-off 
value for tentative group discrimination based on the amino acid sequence similarity of VP6 has been proposed [9]. Recently, putative new RV species were detected in dogs, cats and bats [10-12]. Groups A, D, F and $G$ have been found in birds [1], with a predominance of RVA and RVD shedding [13].

Different mechanisms drive diversity of RVs: point mutations, interspecies transmissions, genetic reassortments and recombinations $[14,15]$. However, virus-host coevolution remains the major evolutionary pattern reported for RVs [16] and reassortment events mainly occur between strains of the same RV group [17, 18]. Nevertheless, some natural reassortants show characteristics suggestive of mixed host species origins [19] and a potential for crossgroup reassortment was revealed for RVA and RVD [20]. As previously shown for a RVD strain [20], typing based only on a few genome segments can be misleading. Thus, definitive RV type characterization necessitates whole genome sequencing [19, 21-23]. The Rotavirus Classification Working Group (RCWG) proposed a uniforme nomenclature for RVA strains based on nucleotide identity cut-off values and allowing to determine the genotype of each genome segment [24].

The prevalence, phylogenetic relation and clinical importance of avian RVs have been described for chickens and turkeys in numerous countries [13, 25-28], but rarely in Africa where the virus may cause dramatic economic losses in particular for subsistence farmers. Avian RVA shedding by diarrheic domestic poultry in Nigeria has been reported for the first time in 2010 [29], without genetic information. Although it is suspected that other poultry species are susceptible to RVs, there is only limited evidence so far. Cross-species transmission may occur when different bird species intermingle, e.g. in backyard farms and live bird markets. Here we investigated genetic diversity of RVA as well as RVD strains circulating in Nigeria to understand transmission pathways and host range.

\section{Methods}

\section{Sample collection}

In 2011 and 2013, fecal samples $(n=349)$ were collected from domestic birds in Ogun and Oyo States, Southwestern Nigeria (Table 1). The samples were collected from different farm types (classified as backyard farms, Farm type 1: farms with less than 500 birds, Farm type 2: farms with between 500 and 10,000 birds, and Farm type 3: farms with over 10,000 birds) and at live bird markets (Table 1$)$. The collection sites $(n>40)$ were randomly selected to represent the avian RV situation within the different farm types. In Oyo state, no birds were sampled in backyard farms. Besides chickens (Gallus gallus domesticus; $n=255$ ), ducks (Anas platyrhynchos; $n=24$ ), guinea fowls (Numida meleagris;
Table 1 Demographic characteristics and rotavirus A (RVA) and $\mathrm{D}$ (RVD) shedding

\begin{tabular}{|c|c|c|c|c|c|c|}
\hline \multirow[t]{3}{*}{ Sample information } & \multicolumn{2}{|c|}{ Dataset } & \multicolumn{4}{|c|}{ Rotavirus positivity } \\
\hline & \multirow[b]{2}{*}{$\mathrm{N}$} & \multirow[b]{2}{*}{$\%$} & \multicolumn{2}{|c|}{ RVA } & \multicolumn{2}{|c|}{ RVD } \\
\hline & & & $\mathrm{n}$ & $\%$ & $n$ & $\%$ \\
\hline \multicolumn{7}{|l|}{ Year of sample collection } \\
\hline 2011 & 199 & 57 & 59 & 29.6 & 82 & 41.2 \\
\hline 2013 & 150 & 43 & 67 & 44.7 & 29 & 19.3 \\
\hline \multicolumn{7}{|l|}{ Observed symptoms } \\
\hline Diarrhea or increased mortality & 158 & 45.3 & 29 & 18.4 & 45 & 28.5 \\
\hline None & 107 & 30.7 & 57 & 53.3 & 42 & 39.3 \\
\hline No information & 84 & 24.1 & 40 & 47.6 & 24 & 28.6 \\
\hline \multicolumn{7}{|l|}{ Age group } \\
\hline 1 (1-25 days) & 76 & 21.8 & 23 & 30.3 & 22 & 28.9 \\
\hline 2 (26-140 days) & 117 & 33.5 & 42 & 35.9 & 63 & 53.8 \\
\hline 3 (>140 days) & 156 & 44.7 & 61 & 39.1 & 26 & 16.7 \\
\hline \multicolumn{7}{|l|}{ Species } \\
\hline Chicken & 255 & 73.1 & 82 & 32.2 & 92 & 36.1 \\
\hline Other & 94 & 26.9 & 44 & 46.8 & 19 & 20.2 \\
\hline \multicolumn{7}{|l|}{ State } \\
\hline Ogun & 249 & 71.3 & 99 & 39.8 & 70 & 28.1 \\
\hline Oyo & 100 & 28.7 & 27 & 27 & 41 & 41 \\
\hline \multicolumn{7}{|l|}{ Collection site } \\
\hline Backyard farm & 18 & 5.2 & 5 & 27.8 & 5 & 27.8 \\
\hline Farm 1 (<500 animals) & 60 & 17.2 & 14 & 23.3 & 6 & 10 \\
\hline Farm $2(500 \leq x \leq 10,000$ animals $)$ & 99 & 28.4 & 32 & 32.3 & 36 & 36.4 \\
\hline Farm 3 (>10,000 animals) & 95 & 27.2 & 31 & 32.6 & 49 & 51.6 \\
\hline Live bird market & 77 & 22.1 & 44 & 57.1 & 15 & 19.5 \\
\hline
\end{tabular}

$n=25$ ), pigeons (Columba livia; $n=19)$, quails (Coturnix coturnix; $n=16$ ) and turkeys (Meleagris gallopavo; $n=10$ ) were included. In 2011, age and health status of the flocks were recorded. In 2013, various bird species were sampled irrespective of their health status.

Samples were directly placed on ice, transported to the laboratory and preserved at $-20{ }^{\circ} \mathrm{C}$ until shipment to Luxembourg, where they were stored at $-80{ }^{\circ} \mathrm{C}$ until further processing.

\section{RNA extraction}

Feces were resuspended in $500 \mu \mathrm{l}$ of virus transport medium [30]. Samples were cleared at $2200 \mathrm{rpm}$ for $20 \mathrm{~min}$ and $140 \mu \mathrm{l}$ of supernatant medium was used for RNA extraction using QIAamp Viral RNA Mini Kits (Qiagen, Venlo, The Netherlands).

\section{Rotavirus detection}

Prior to the RT-PCR, double-stranded RNA was denatured at $95{ }^{\circ} \mathrm{C}$ for 2 min followed by cooling on ice. Detection and sequencing PCRs were performed using 
the Qiagen one-step RT-PCR kit (Qiagen). RVA positivity was detected by real-time RT-PCR targeting the VP6 gene [13] and/or by the conventional PCR targeting the NSP4 gene [25]. RVD was detected by a real-time RT-PCR targeting the VP6 gene [13]. Suboptimal probe binding due to frequent mutations at the binding sites were suspected based on low fluorescence signals in both real-time RT-PCRs and detection was therefore confirmed by gel electrophoresis. The Avian RVA (cell culture supernatant, strain RVA/Chicken-tc/DEU/02V0002G3/2002/G19P[30]) and RVD (intestinal content, strain RVD/Chicken-wt/ NLD/10 V0133/2010/GXP[X]) strains, kindly provided by Dr. P. Otto (Friedrich-Loeffler Institute, Germany), served as positive controls.

\section{Sequencing and genotype characterization}

For sequencing of RVA and RVD positive samples, additional primers were designed and evaluated with Geneious software (version 7.1.7; Biomatters Limited; Auckland, New Zealand [http://www.geneious.com]) [31] and Primer3Plus (http://primer3plus.com/cgi-bin/ dev/primer3plus.cgi) for partial amplification of VP4, VP6, VP7 of RVA and VP6 and VP7 of RVD (Additional file 1). NSP4 sequences were obtained by using the detection primers [25]. Amplification conditions were as follows: $50{ }^{\circ} \mathrm{C}$ for $30 \mathrm{~min}, 94{ }^{\circ} \mathrm{C}$ for $15 \mathrm{~min}$ with subsequent 40 cycles of denaturation at $94{ }^{\circ} \mathrm{C}$ for $30 \mathrm{~s}$, annealing at $53{ }^{\circ} \mathrm{C}$ for $30 \mathrm{~s}$, extension at $72{ }^{\circ} \mathrm{C}$ for $60 \mathrm{~s}$. RTPCR was performed with $3 \mu \mathrm{l}$ of RNA and $22 \mu \mathrm{l}$ of PCR mix (containing 1× Qiagen OneStep RT-PCR Buffer, $1.25 \mathrm{mM} \mathrm{MgCl}_{2}$, dNTPs at $400 \mu \mathrm{M}$ each, $1 \mu \mathrm{l}$ of Qiagen OneStep RT-PCR Enzyme Mix, $0.5 \mu \mathrm{M}$ of each primer and PCR-grade $\mathrm{H}_{2} \mathrm{O}$ to adjust the final volume). Positive samples were identified by gel-electrophoresis and amplicons of the appropriate size excised from the gel and purified with the QIAquick gel extraction kit (Qiagen). Specific PCR products were directly purified using the JetQuick $^{\mathrm{m}}$ extraction kit (Genomed, Löhne, Germany). Sequencing was performed using the BigDye terminator kit (Applied Biosystems, Foster City, CA) on an ABI 3130 sequencer (Applied Biosystems). RVA genotype classification of partial gene sequences was done as recommended by RCWG [24, 32].

\section{Phylogenetic analysis}

RV sequences were assembled in Geneious software [31] and trimmed before further analysis. RV sequences from this study were compared to all avian RV sequences available in GenBank database (http://www.ncbi.nlm.nih.gov/Genbank/index.html). Alignments were obtained by applying the ClustalW multiple alignment method (EMBL; Heidelberg, Germany) and poorly aligned regions trimmed using Gblocks as implemented in SeaView software (version 4; CNRS; Villeurbanne, France [http://doua.prabi.fr/software/seaview]) [33-35]. For each alignment, the best-fit model of nucleotide substitution was selected using JModeltest (https://github.com/ddarriba/jmodeltest2) [36] (Additional file 2). Bayesian analyses were applied as statistical inference methods of the phylogenetic analysis, as described before [37]. Representative isolates for which sequences from several genes were obtained or that were detected in new RV host species are shown in Figs. 1, 2 and 3. Additional phylogenetic trees based on all long sequences from this study and including also more GenBank sequences can be found in the supplementary material (Additional files 3, 4, 5 and 6). Only posterior probability values $>0.7$ are depicted in the phylogenetic trees.

\section{Statistical analyses}

Statistical analyses were performed in R software (version 3.1.0.; $\mathrm{R}$ Foundation for Statistical Computing, Vienna, Austria [https://www.r-project.org/]) [38]. Twosided Fisher's exact test was applied to identify potential factors influencing virus shedding in chickens: age group, symptoms (diarrhea, increased mortality or no overt symptoms) and RVA-RVD-coinfection (yes/no). Logistic regression analysis was applied to predict whether RVA shedding is affected by age group and RVA-RVD-coinfection. The overall significance of the models was assessed by chi-squared tests and the individual effect of the categorical factors of the model by Wald tests. The packages aod [39] and Rcpp [40] in R were used to test for association between the categorical variables and RV shedding.

\section{Results}

\section{Rotavirus shedding}

In total, $36.1 \%(126 / 349,95 \%$ CI: $31-41 \%)$ and $31.8 \%$ (111/349, 95\% CI: $27-37 \%)$ of all fecal samples were positive for avian RVA and RVD (Table 1). RVA and RVD co-infection was revealed for 15.2\% (53/349, 95\% CI: $12-19 \%)$ of the birds. RVD shedding among chickens was increased in farms with more than 10,000 birds $(p=0.04)$ and significantly higher shedding rates were observed in Oyo than in Ogun state (41.3 and 30.5\%; $p=0.007)$. There was no association between RVA shedding among chickens and collection site or state. Mostly asymptomatic chickens shed RVs. When taking into account only the chickens for which the health status was recorded $(n=225)$, only $18.9 \%(28 / 148)$ of the RVA positive chickens and only $29.7 \%$ (44/148) of the RVD positive chickens and were symptomatic. Thus symptomatic chicken were significantly less likely to shed RVA and RVD (Odds Ratio $=0.2$ and $0.3,95 \% \mathrm{CI}=0.1-$ 0.4 and $0.3-0.8, p<0.001$ and 0.01$)$. Logistic regression analysis predicted that RVA positivity is affected by age and RVD coinfection $(p=0.002)$. RVA shedding was 


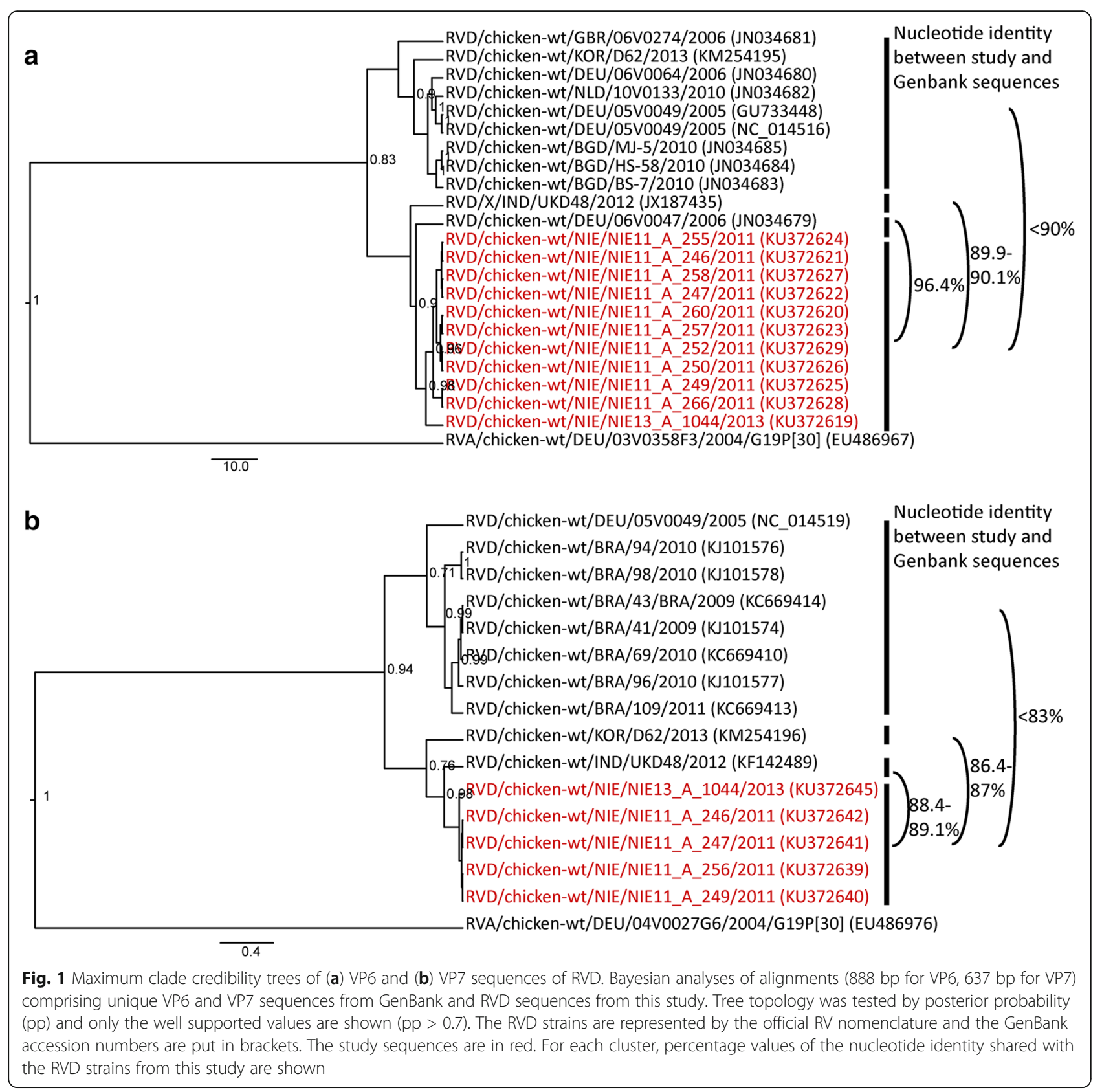

significantly increased in chickens that shed also RVD (Odds Ratio $=2.4,95 \% \mathrm{CI}=1.5-4.6, p=0.004)$. Although the overall effect of age group was significant in the Wald test $\left(\mathrm{X}^{2}=39.9\right.$, degrees of freedom $=3$, $p<0.001)$, a significant difference between age groups could only be revealed for age groups 1 and $2\left(x^{2}=5.0\right.$, degrees of freedom $=1, p=0.025$ ). Chickens aged 26140 days were more likely to shed RVA than 1-25 days old chickens (Odds Ratio $=1.11,95 \% \mathrm{CI}=0.57-2.16$ ).

Besides chickens, other bird species were also positive for RVA (i.e. 23/25 guinea fowls, 13/19 pigeons, 2/16 quails, 5/24 ducks and 1/10 turkeys) and RVD (i.e. $3 / 25$ guinea fowls, $11 / 19$ pigeons, $3 / 16$ quails, $1 / 24$ ducks and
$1 / 10$ turkeys). The majority $(63.8 \%, 60 / 94)$ of those nonchicken birds were sampled at live bird markets.

\section{Sequence analysis}

Sequencing success was generally low and dependent on host species, RV group and genome segment. This was most probably due to poor sample quality, low copy numbers in fecal samples and/or the low specificity of primers designed on the basis of only a few avian RV sequences available in public databases. Nevertheless, sequencing data was obtained from 69\% (87/126) of RVA (Table 2) and $100 \%(111 / 111)$ of RVD positive samples. 


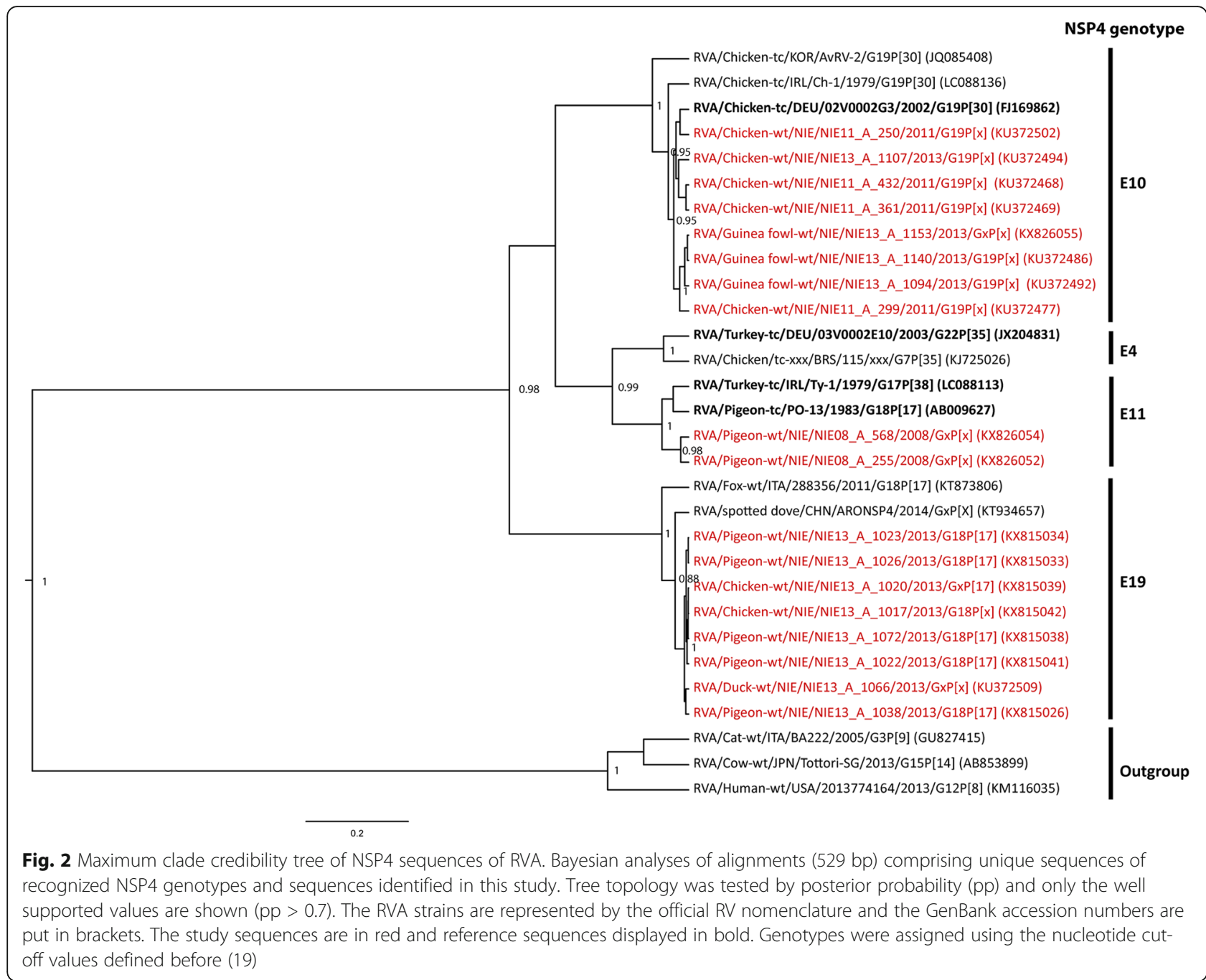

RVD sequences showed little diversity ( $>98 \%$ nucleotide identity for VP6 and $>99 \%$ nucleotide identity for VP7) and were clearly distinct from RVA (Fig. 1). Both phylogenetic and nucleotide identity analyses of partial RVD sequences showed that all VP6 sequences grouped into two major clusters (Fig. 1a) with less than 90\% nucleotide identity. Similarly, partial VP7 sequences grouped into two major clusters with less than $83 \%$ nucleotide identity (Fig. 1b).

Genotype assignment of RVA can be retrieved from Table 2. In general, RVA strains from the same place and time point had highly similar sequences. On the phylogenetic tree of NSP4, the first diverging event led to two well supported lineages: one comprising the avian and the other the mammalian RVA strains (Fig. 2). All avian NSP4 strains fell into four clusters, corresponding to four distinct NSP4 genotypes (Fig. 2, Additional file 3). Genotype E10 (reference strain RVA/Chicken-tc/DEU/02V0002G3/ 2002/G19P[30]) regrouped most of our sequences from chickens and guinea fowls. The remaining sequences from various bird species (including pigeons, ducks, chickens, guinea fowls and quail) were closely related to two fox and dove sequences (strains: RVA/Fox-tc/ITA/288356/ 2011/G18P[17] and RVA/spotted dove/CHN/ARONSP4/ 2014/GxP[X]). Those sequences were assigned to the new NSP4 genotype, E19 (Table 2).

Most partial VP4 sequences from chickens and guinea fowls clustered together with RVA/Chicken-tc/DEU/ 06 V0661/2006/G19P[31] within genotype P[31] (Fig. 3a; Additional file 3). Similar to NSP4, all pigeon and duck sequences and a few chicken and guinea fowl sequences clustered together and were assigned to genotype $\mathrm{P}$ [17], that includes also the above fox strain and the reference strain RVA/Pigeon-tc/PO-13/1983/G18P[17]. The phylogenetic trees of NSP4 and VP4 had topologies similar to those obtained for VP6 and VP7 (Figs. 2 and 3; Additional files 5 and 6). Most chicken and guinea fowl strains were assigned to VP6 genotype I11 and VP7 genotype G19. The remaining strains were closely related to the fox and the pigeon PO-13 strains and 


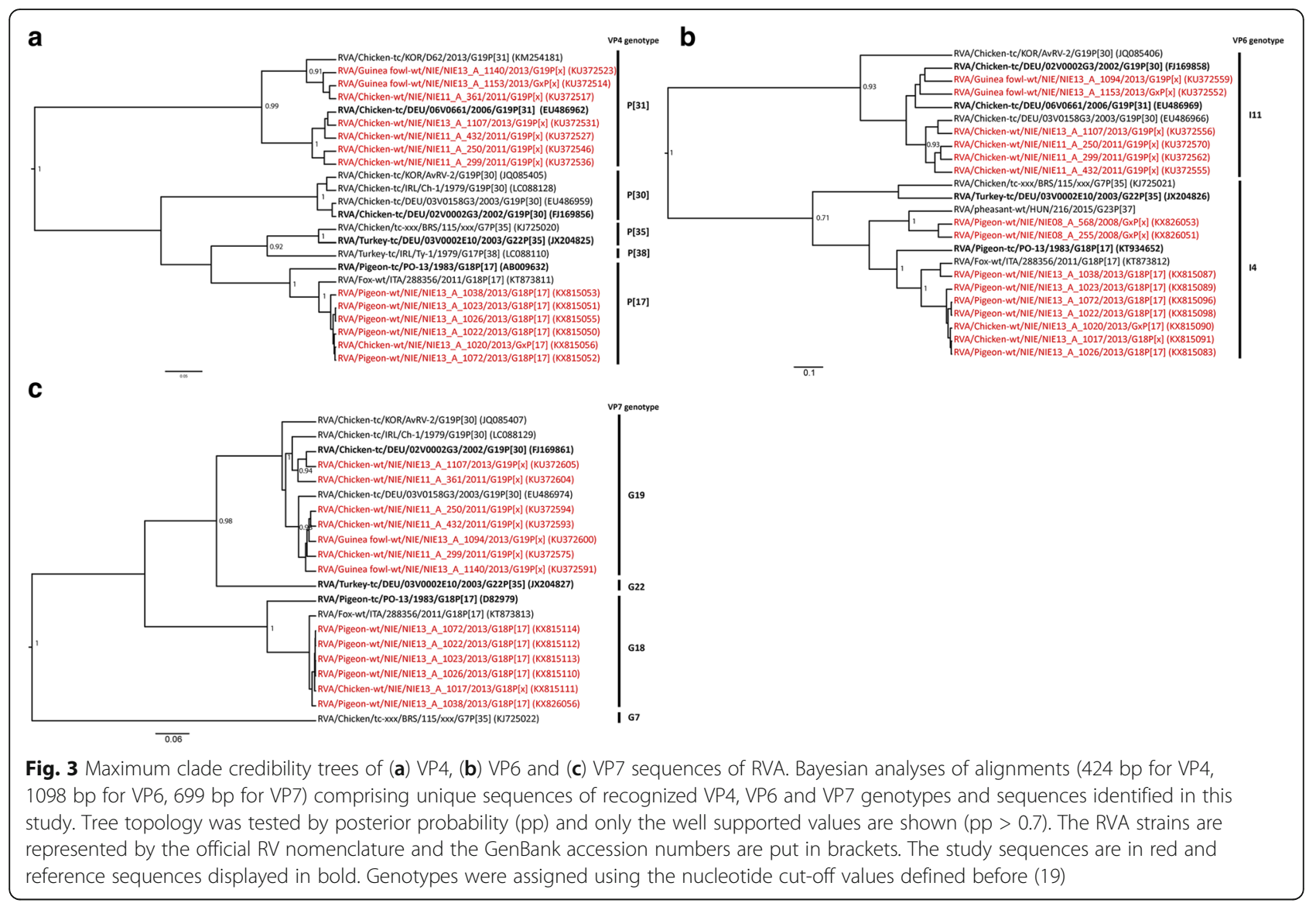

assigned to VP6 genotype I4 and VP7 genotype G18 (Fig. $3 \mathrm{~b}$ and c).

Thus, the majority of our sequences had one of the following two genotype constellations: G19-P[31]-I11-E10 or G18-P[17]-I4-E19. However, 7/87 samples showed different genome constellations possibly indicative of genetic reassortment (Table 2).

\section{Discussion}

In Nigeria, several viral diseases affect productivity and economic success of the poultry industry [41-43]. In this study we show that RV infections among different bird species may constitute an additional threat. High levels of RVA and RVD shedding were detected in species such as guinea fowls and ducks, for which genetic and epidemiological data on RVs are largely missing. However, the effect of RV infection on animal health seemed limited as mostly asymptomatic birds were found to shed RVs. This is in line with previous studies that reported subclinical RV infections mostly in adult birds [4, 7]. Subclinical shedding contributes considerably to the maintenance of a high viral contamination in the farm and environment that may, in turn, be an important source of infection for younger animals. Growth performance and egg production may also suffer, in particular in large farms ( $>500$ animals) [27].

The genetic diversity of the Nigerian RV strains was high. The Nigerian sequences considerably extend the current RV sequence database and will be useful to increase specificity of the molecular detection assays. We showed that RVD is not solely shed by chickens, but also by pigeons and guinea fowls from which partial sequences were obtained (e.g. GenBank accession numbers KU372630 and KX907137). Phylogenetic tree topology of partial gene sequences suggests at least two separate lineages of VP6 and VP7 of RVD (Fig. 1). Full length RVD sequences of these and other genes will be required to define genotyping criteria.

Similarly, RVA was found in bird species other than chickens. Most guinea fowls sampled at live bird markets were infected by the same strains as chickens (G19$\mathrm{P}[31]-I 11-\mathrm{E} 10)$. Also G18-P[17]-I4-E19 was found in pigeons, chickens (Figs. 2 and 3), guinea fowls, quails and ducks (Additional file 3), suggesting host permissiveness of these strains when different bird species are mixed, for instance at live bird markets. In this context, it is interesting that avian RVA G18-P[17]-I4-E19 strains were distantly related to the other typical chicken RVs, and closely related to a fox RV strain only recently 
Table 2 Genetic composition of study sequences

\begin{tabular}{|c|c|c|c|c|c|c|c|c|c|}
\hline \multirow[t]{3}{*}{$\overline{\text { Year }}$} & \multirow[t]{3}{*}{ State } & \multirow[t]{3}{*}{ Area } & \multirow[t]{3}{*}{ Collection site } & \multirow[t]{3}{*}{ Bird species } & \multirow[t]{3}{*}{ Animal Code } & \multicolumn{4}{|l|}{ RVA gene } \\
\hline & & & & & & \multirow{2}{*}{$\begin{array}{l}\text { VP7 } \\
\text { Genotype }\end{array}$} & \multirow{2}{*}{$\begin{array}{l}\text { VP4 } \\
\text { Genotype }\end{array}$} & \multirow{2}{*}{$\begin{array}{l}\text { VP6 } \\
\text { Genotype }\end{array}$} & \multirow{2}{*}{$\begin{array}{l}\text { NSP4 } \\
\text { Genotype }\end{array}$} \\
\hline & & & & & & & & & \\
\hline \multirow[t]{30}{*}{2011} & \multirow[t]{18}{*}{ Ogun } & \multirow[t]{15}{*}{ Owode-Egba } & \multirow[t]{15}{*}{ Farm type 3} & \multirow[t]{15}{*}{ Chicken } & NIE11_A_255 & $\mathrm{G} 19^{\mathrm{a}}$ & $\mathrm{P}[31]^{\mathrm{a}}$ & 111 & E10 \\
\hline & & & & & NIE11_A_252 & $\mathrm{G} 19^{\mathrm{a}}$ & $\mathrm{P}[31]^{\mathrm{a}}$ & 111 & E10 \\
\hline & & & & & NIE11_A_254 & G19 & $\mathrm{P}[31]^{\mathrm{a}}$ & 111 & E10 \\
\hline & & & & & NIE11_A_242 & $\mathrm{G} 19^{\mathrm{a}}$ & $\mathrm{P}[31]^{\mathrm{a}}$ & 111 & E10 \\
\hline & & & & & NIE11_A_251 & $\mathrm{G} 19^{\mathrm{a}}$ & $\mathrm{P}[31]^{\mathrm{a}}$ & 111 & E10 \\
\hline & & & & & NIE11_A_253 & G19 & $\mathrm{P}[31]^{\mathrm{a}}$ & 111 & E10 \\
\hline & & & & & NIE11_A_256 & G19 & $P[31]^{a}$ & 111 & $\mathrm{E} 10^{\mathrm{a}}$ \\
\hline & & & & & NIE11_A_257 & G19 & $P[31]^{a}$ & 111 & E10 \\
\hline & & & & & NIE11_A_260 & G19 & $P[31]^{a}$ & 111 & E10 \\
\hline & & & & & NIE11_A_250 & G19 & $P[31]^{a}$ & 111 & E10 \\
\hline & & & & & NIE11_A_249 & G19 & $\mathrm{P}[31]^{\mathrm{a}}$ & 111 & E10 \\
\hline & & & & & NIE11_A_247 & $\mathrm{G} 19^{\mathrm{a}}$ & $\mathrm{P}[31]^{\mathrm{a}}$ & $111^{a}$ & E10 \\
\hline & & & & & NIE11_A_246 & $\mathrm{G} 19^{\mathrm{a}}$ & $\mathrm{P}[31]^{\mathrm{a}}$ & $111^{a}$ & E10 \\
\hline & & & & & NIE11_A_266 & $\mathrm{G} 19^{\mathrm{a}}$ & $\mathrm{P}[31]^{\mathrm{a}}$ & 111 & n.s. \\
\hline & & & & & NIE11_A_258 & $\mathrm{G} 19^{\mathrm{a}}$ & $\mathrm{P}[31]^{\mathrm{a}}$ & 111 & n.s. \\
\hline & & Ajebo & Farm type 2 & Chicken & NIE11_A_461 & n.s. & n.s. & n.s. & E10 \\
\hline & & ljebu-Ode & Farm type 3 & Chicken & NIE11_A_450 & G19 & $P[31]^{a}$ & 111 & E10 \\
\hline & & & & & NIE11_A_441 & G19 & $P[31]^{a}$ & 111 & n.s. \\
\hline & \multirow[t]{12}{*}{ Oyо } & \multirow[t]{4}{*}{ Ibadan North } & \multirow[t]{4}{*}{ Farm type 2} & \multirow[t]{4}{*}{ Chicken } & NIE11_A_299 & G19 & $\mathrm{P}[31]^{\mathrm{a}}$ & 111 & E10 \\
\hline & & & & & NIE11_A_295 & G19 & $P[31]^{\mathrm{a}}$ & 111 & E10 \\
\hline & & & & & NIE11_A_300 & G19 & $P[31]^{a}$ & 111 & n.s. \\
\hline & & & & & NIE11_A_298 & G19 & $\mathrm{P}[31]^{\mathrm{a}}$ & $111^{a}$ & n.s. \\
\hline & & \multirow[t]{8}{*}{ Ilora } & Farm type 2 & Chicken & NIE11_A_365 & n.s. & n.s. & n.s. & E10 \\
\hline & & & & & NIE11_A_369 & n.s. & n.s. & n.s. & E10 \\
\hline & & & & & NIE11_A_366 & G19 & $\mathrm{P}[31]^{\mathrm{a}}$ & $111^{a}$ & E10 \\
\hline & & & & & NIE11_A_362 & G19 & $P[31]^{a}$ & $111^{a}$ & E10 \\
\hline & & & & & NIE11_A_361 & G19 & $\mathrm{P}[31]^{\mathrm{a}}$ & $111^{a}$ & E10 \\
\hline & & & & & NIE11_A_363 & n.s. & n.s. & n.s. & E10 \\
\hline & & & & & NIE11_A_436 & n.s. & n.s. & n.s. & E10 \\
\hline & & & Farm type 1 & Chicken & NIE11_A_432 & G19 & $\mathrm{P}[31]^{\mathrm{a}}$ & 111 & E10 \\
\hline 2013 & Ogun & Adatan & Live bird market & Chicken & NIE13_A_1134 & G19 & $\mathrm{P}[31]^{\mathrm{a}}$ & n.s. & E10 \\
\hline & & & & & NIE13_A_1136 & G19 & n.s. & n.s. & E10 \\
\hline & & & & & NIE13_A_1138 & G19 & $\mathrm{P}[31]^{\mathrm{a}}$ & n.s. & n.s. \\
\hline & & Ago-lka & Live bird market & Guinea fowl & NIE13_A_1150 & G19 & $P[31]^{\mathrm{a}}$ & n.s. & E10 \\
\hline & & & & & NIE13_A_1143 & G19 & $\mathrm{P}[31]^{\mathrm{a}}$ & n.s. & E10 \\
\hline & & & & & NIE13_A_1140 & G19 & $\mathrm{P}[31]^{\mathrm{a}}$ & n.s. & E10 \\
\hline & & & & & NIE13_A_1141 & G19 & $\mathrm{P}[31]^{\mathrm{a}}$ & n.s. & n.s. \\
\hline & & & & & NIE13_A_1145 & G19 & $P[31]^{a}$ & 111 & E10 \\
\hline & & & & & NIE13_A_1152 & G19 & $\mathrm{P}[31]^{\mathrm{a}}$ & 111 & n.s. \\
\hline & & & & & NIE13_A_1142 & G19 & $\mathrm{P}[31]^{\mathrm{a}}$ & n.s. & E10 \\
\hline & & & & & NIE13_A_1144 & G19 & $\mathrm{P}[31]^{\mathrm{a}}$ & 111 & E10 \\
\hline & & & & & NIE13_A_1146 & G19 & n.s. & n.s. & E10 \\
\hline & & & & & NIE13_A_1092 & G19 & $\mathrm{P}[31]^{\mathrm{a}}$ & 111 & E10 \\
\hline & & & & & NIE13_A_1095 & G19 & $\mathrm{P}[31]^{\mathrm{a}}$ & n.s. & E10 \\
\hline
\end{tabular}


Table 2 Genetic composition of study sequences (Continued)

\begin{tabular}{|c|c|c|c|c|c|c|c|c|}
\hline & & & & NIE13_A_1094 & G19 & $\mathrm{P}[31]^{\mathrm{a}}$ & 111 & E10 \\
\hline & & & & NIE13_A_1096 & G19 & $\mathrm{P}[31]^{\mathrm{a}}$ & 111 & E10 \\
\hline & & & & NIE13_A_1149 & G19 & $\mathrm{P}[31]^{\mathrm{a}}$ & 111 & n.s. \\
\hline & & & & NIE13_A_1093 & G19 & $\mathrm{P}[31]^{\mathrm{a}}$ & 111 & E10 \\
\hline & & & & NIE13_A_1147 & G19 & n.s. & 111 & E10 \\
\hline & & & & NIE13_A_1091 & G19 & $\mathrm{P}[31]^{\mathrm{a}}$ & 111 & E10 \\
\hline & & & & NIE13_A_1153 & $\mathrm{G} 19^{\mathrm{a}}$ & $\mathrm{P}[31]^{\mathrm{a}}$ & 111 & E10 \\
\hline & & & Duck & NIE13_A_1066 b & n.s. & $\mathrm{P}[31]^{\mathrm{a}}$ & n.s. & E19 \\
\hline & Lafenwa & Backyard farm & Chicken & NIE13_A_1104 & n.s. & $P[31]^{a}$ & n.s. & E10 \\
\hline & & & & NIE13_A_1107 & G19 & $\mathrm{P}[31]^{\mathrm{a}}$ & 111 & E10 \\
\hline & Alabata & Farm type 2 & Chicken & NIE13_A_1040 & G19 & $\mathrm{P}[31]^{\mathrm{a}}$ & n.s. & E10 \\
\hline & Itoku & Live bird market & Guinea fowl & NIE13_A_1008 b & G19 & $\mathrm{P}[31]^{\mathrm{a}}$ & n.s. & E19 \\
\hline & Ewekoro & Farm type 1 & Chicken & NIE13_A_1013 & n.s. & n.s. & n.s. & E19 \\
\hline & & & & NIE13_A_1017 & G18 & $P[17]^{a}$ & 14 & E19 \\
\hline & & & & NIE13_A_1019 & n.s. & n.s. & 14 & $\mathrm{E} 19^{\mathrm{a}}$ \\
\hline & & & & NIE13_A_1020 & n.s. & $P[17]^{a}$ & 14 & E19 \\
\hline & Abeokuta north & Live bird market & Pigeon & NIE13_A_1022 & G18 & $\mathrm{P}[17]$ & 14 & E19 \\
\hline & & & & NIE13_A_1023 & G18 & $\mathrm{P}[17]$ & 14 & E19 \\
\hline & & & & NIE13_A_1024 & n.s. & n.s. & 14 & E19 \\
\hline & & & & NIE13_A_1025 & G18 & $P[17]$ & 14 & E19 \\
\hline & & & & NIE13_A_1026 & G18 & $\mathrm{P}[17]$ & 14 & E19 \\
\hline & & & & NIE13_A_1128 & n.s. & n.s. & 14 & E19 \\
\hline & & & & NIE13_A_1129 & n.s. & $P[17]^{a}$ & 14 & E19 \\
\hline & & & Duck & NIE13_A_1068 & n.s. & n.s. & 14 & E19a \\
\hline & Odeda & Farm type 1 & Chicken & NIE13_A_1028 & n.s. & n.s. & $14^{\mathrm{a}}$ & E19 \\
\hline & & & & NIE13_A_1169 b & n.s. & $P[17]^{a}$ & 111 & E10 \\
\hline & & Farm type 2 & Chicken & NIE13_A_1039 & n.s. & n.s. & 14 & E19 \\
\hline & & & & NIE13_A_1045 b & $\mathrm{G} 19^{\mathrm{a}}$ & n.s. & $14^{\mathrm{a}}$ & E10 \\
\hline & & & & NIE13_A_1047 & n.s. & n.s. & $14^{\mathrm{a}}$ & E19 \\
\hline & Abeokuta south & Live bird market & Pigeon & NIE13_A_1036 & G18 & $P[17]^{a}$ & 14 & E19 \\
\hline & & & & NIE13_A_1037 b & $\mathrm{G} 19^{\mathrm{a}}$ & n.s. & 14 & E19 \\
\hline & & & & NIE13_A_1038 & G18 & $\mathrm{P}[17]$ & 14 & E19 \\
\hline & & & Duck & NIE13_A_1164 & n.s. & n.s. & n.s. & E19 \\
\hline & & & Chicken & NIE13_A_1081 & n.s. & n.s. & n.s. & E19 \\
\hline & & & & NIE13_A_1085 & n.s. & n.s. & 14 & E19 \\
\hline & & & & NIE13_A_1138 b & n.s. & $P[17]^{a}$ & n.s. & E10 \\
\hline & & Backyard farm & Pigeon & NIE13_A_1072 & G18 & $\mathrm{P}[17]$ & 14 & E19 \\
\hline & & & & NIE13_A_1074 & n.s. & n.s. & $14^{\mathrm{a}}$ & E19 \\
\hline & & & & NIE13_A_1075 b & $\mathrm{G} 19^{\mathrm{a}}$ & n.s. & $14^{\mathrm{a}}$ & E19 \\
\hline \multirow[t]{4}{*}{ Oyo } & Akinyele & Live bird market & Guinea Fowl & NIE13_A_1069 & n.s. & n.s. & $14^{\mathrm{a}}$ & E19 \\
\hline & & & & NIE13_A_1070 & n.s. & n.s. & $14^{\mathrm{a}}$ & E19 \\
\hline & & & & NIE13_A_1071 & n.s. & n.s. & $14^{\mathrm{a}}$ & E19 \\
\hline & Ibadan North & Live bird market & Quail & NIE13_A_1119 & n.s. & n.s. & $14^{\mathrm{a}}$ & E19 \\
\hline
\end{tabular}

a Sequence too short for definite genotype allocation using the criteria of the RCWG

b Potential reassortants

Bold face sequences are shown in phylogenetic tree of Figs. 2 and 3 
published in GenBank. Phylogenetic analyses revealed early divergence between mammalian and avian RVA strains [18] and only few inconclusive examples of mammalian-bird transmission of RVA have been reported [44-46]. It remains elusive whether the RVA strain originated from an infected fox or from an infected bird prey.

The G18-P[17]-I4-E19 strains were frequently found in pigeons in our study but also in a Spotted dove (Streptopelia chinensis) in China (NSP4 only) and in a pigeon (VP4, VP6, VP7) back in 1983 [46]. To investigate whether Columbidae are the principal reservoir of this group of RVA strains, we screened, with the same approach, fecal samples of wild pigeons $(n=161)$ collected in Nigeria in 2008 (data not shown). The NSP4 fragments obtained from a Streptopelia roseogrisea and a Turtur abyssinicus were assigned to another genotype, E11 and, the VP6 fragments, although assigned to genotype I4, were most similar to a recently published pheasant strain (Figs. 2 and $3 \mathrm{~b}$ ), and not to the fox strain. Thus, no statement can be made on the principal reservoir of G18-P[17]-I4-E19.

Consistent with previous studies [13, 16, 18, 47-49], we found a clearly separated and independent evolution of RVA and RVD strains (Figs. 1, 2 and 3) and a high proportion of RVA/RVD co-infections. RVA/RVD coinfections may lead to natural cross-group reassortment, which may be further facilitated by identical gene termini $[18,20]$. Natural RVA-RVD cross-group reassortants have not yet been described and we found only preliminary indications of reassortment between RVA strains among our sequences. Definite characterization of such reassortants would necessitate virus isolation and full genome sequencing. Current reverse genetic approaches for RVA [50] will facilitate the rescue of reassortants in vitro and evaluation of the consequence of natural co-infections on virus evolution and clinical outcome.

\section{Conclusion}

We show that co-circulation of diverse RV strains in mixed bird farms and at live bird markets promotes interspecies transmission. The study stresses once more that rearing and trading conditions in rural Africa favor emergence of novel viruses with low host-specificity and with only partly understood economic and clinical impact.

\section{Additional files}

Additional file 1: Primers used for the detection of avian group $A$ and $D$ rotaviruses by real-time RT-PCR and for amplification of segments of VP4, VP6, VP7 and NSP4 for sequencing. (PDF $198 \mathrm{~kb}$ )
Additional file 2: Best-fit models of nucleotide substitution that were selected for each phylogenetic analysis using JModeltest (https:// github.com/ddarriba/jmodeltest2). (PDF 167 kb)

Additional file 3: Maximum clade credibility tree of partial NSP4 gene sequences of Rotavirus group A (RVA). (PDF $279 \mathrm{~kb}$ )

Additional file 4: Maximum clade credibility tree of partial VP4 gene sequences of Rotavirus group A (RVA). (PDF 288 kb)

Additional file 5: Maximum clade credibility tree of partial VP6 gene sequences of Rotavirus group A (RVA). (PDF $312 \mathrm{~kb}$ )

Additional file 6: Maximum clade credibility tree of partial VP7 gene sequences of Rotavirus group A (RVA). (PDF $305 \mathrm{~kb}$ )

\section{Abbreviations}

ICTV: International Committee on Taxonomy of Viruses; NSP: Nonstructural proteins; RCWG: Rotavirus Classification Working Group; RV: Rotavirus; RVA-RVH: Rotavirus groups A to H; RVs: Rotaviruses

\section{Acknowledgements}

We thank Dr. P. Otto, Friedrich-Loeffler Institute, Germany who kindly provided the reference rotavirus strains. Moreover, we are grateful to all the veterinarians and farmers who were involved in sample collection in Nigeria.

\section{Funding}

This study was funded by the Ministry of Foreign and European Affairs, Luxembourg (project "Microbiology for development IV"), who was neither involved in study design, data collection and interpretation, nor in the decision to submit the work for publication.

\section{Availability of data and materials}

Sequences were submitted to GenBank database (https://

www.ncbi.n/m.nih.gov/genbank/) under accession numbers KU372466 to KU372648, KX815011 to KX815120, KX826051 to KX826056 and KX907137.

\section{Authors' contributions}

OOO, AAO, CAOA, CJS and CPM designed the study, coordinated the sample collection and supervised the laboratory work. AS, OOO, CJS and MP performed the laboratory work and analyzed the data. MP, OOO, CPM, JHM and CJS contributed in writing the manuscript. All authors read and approved the final manuscript.

\section{Competing interests}

The authors declare that they have no competing interests.

Consent for publication

Not applicable

Ethics approval and consent to participate

In Nigeria, no ethical approval is required when samples from animals are collected in a non-invasive manner.

\section{Publisher's Note}

Springer Nature remains neutral with regard to jurisdictional claims in published maps and institutional affiliations.

\section{Author details}

${ }^{1}$ Infectious Diseases Research Unit, Department of Infection and Immunity, Luxembourg Institute of Health, 29 rue Henri Koch, L-4354 Esch-sur-Alzette, Luxembourg. ${ }^{2}$ Department of Veterinary Medicine and Surgery, College of Veterinary Medicine, Federal University of Agriculture, Abeokuta, Ogun State, Nigeria. ${ }^{3}$ Department of Veterinary Medicine, University of Ibadan, Ibadan, Oyo State, Nigeria. 
Received: 21 December 2016 Accepted: 6 June 2017

Published online: 12 June 2017

\section{References}

1. Estes MK, Kapikian AZ. Rotaviruses. In: Knipe DM, Howley PM, editors. Fields Virology. Volume 2. 5th edition. Philadelphia: Lippincott William \& Wilkins; 2007.

2. Parashar UD, Burton A, Lanata C, Boschi-Pinto C, Shibuya K, Steele D, et al. Global mortality associated with rotavirus disease among children in 2004 J Infect Dis. 2009;200(Suppl 1):S9-s15.

3. Holland RE. Some infectious causes of diarrhea in young farm animals. Clin Microbiol Rev. 1990;3:345-75.

4. McNulty MS, Jones RC. Rotaviruses. In: Pattison, McMullin, Bradbury, Alexander, editors. Poultry diseases. 6th edition. Philadelphia: SAUNDERS Elsevier; 2008.

5. Guy JS. Virus infections of the gastrointestinal tract of poultry. Poult Sci. 1998;77:1166-75

6. Otto P, Liebler-Tenorio EM, Elschner M, Reetz J, Lohren U, Diller R. Detection of rotaviruses and intestinal lesions in broiler chicks from flocks with runting and stunting syndrome (RSS). Avian Dis. 2006;50:411-8.

7. Moura-Alvarez J, Chacon JV, Scanavini LS, Nunez LF, Astolfi-Ferreira CS, Jones RC, et al. Enteric viruses in Brazilian turkey flocks: single and multiple virus infection frequency according to age and clinical signs of intestinal disease. Poult Sci. 2013:92:945-55.

8. Desselberger U. Rotaviruses. Virus Res. 2014;190:75-96.

9. Matthijnssens J, Otto PH, Ciarlet M, Desselberger U, Van Ranst M, Johne R. VP6-sequence-based cutoff values as a criterion for rotavirus species demarcation. Arch Virol. 2012;157:1177-82.

10. Mihalov-Kovacs E, Gellert A, Marton S, Farkas SL, Feher E, Oldal M, et al. Candidate new rotavirus species in sheltered dogs, Hungary. Emerg Infect Dis. 2015;21:660-3.

11. Banyai K, Kemenesi G, Budinski I, Foldes F, Zana B, Marton S, et al. Candidate new rotavirus species in Schreiber's bats, Serbia. Infect Genet Evol. 2017:48:19-26.

12. Phan TG, Leutenegger CM, Chan R, Delwart E. Rotavirus I in feces of a cat with diarrhea. Virus Genes. 2017:53:487-90.

13. Otto PH, Ahmed MU, Hotzel H, Machnowska P, Reetz J, Roth B, et al. Detection of avian rotaviruses of groups $a, D, F$ and $G$ in diseased chickens and turkeys from Europe and Bangladesh. Vet Microbiol. 2012;156:8-15.

14. Iturriza-Gomara M, Desselberger U, Gray J. Molecular epidemiology of rotaviruses: genetic mechanisms associated with diversity. In: Desselberger $U$, Gray J, editors. Viral gastroenteritis. Amsterdam: Elsevier Science; 2003. p. 317-44.

15. Martella V, Banyai K, Matthijnssens J, Buonavoglia C, Ciarlet M. Zoonotic aspects of rotaviruses. Vet Microbiol. 2010;140:246-55.

16. Kattoor JJ, Malik YS, Sasidharan A, Rajan VM, Dhama K, Ghosh S, et al. Analysis of codon usage pattern evolution in avian rotaviruses and their preferred host. Infect Genet Evol. 2015;34:17-25.

17. Le Pendu J, Nystrom K, Ruvoen-Clouet N. Host-pathogen co-evolution and glycan interactions. Curr Opin Virol. 2014;7:88-94.

18. Kindler $E_{\text {, Trojnar }}$, Heckel G, Otto PH, Johne R. Analysis of rotavirus species diversity and evolution including the newly determined full-length genome sequences of rotavirus $F$ and G. Infect Genet Evol. 2013;14:58-67.

19. Schumann $T$, Hotzel $H$, Otto $P$, Johne R. Evidence of interspecies transmission and reassortment among avian group a rotaviruses. Virology. 2009:386:334-43.

20. Trojnar E, Otto P, Roth B, Reetz J, Johne R. The genome segments of a group D rotavirus possess group A-like conserved termini but encode group-specific proteins. J Virol. 2010;84:10254-65.

21. Gentsch JR, Laird AR, Bielfelt B, Griffin DD, Banyai K, Ramachandran M, et al. Serotype diversity and reassortment between human and animal rotavirus strains: implications for rotavirus vaccine programs. J Infect Dis. 2005; 192(Suppl 1):S146-59.

22. McDonald SM, Matthijnssens J, McAllen JK, Hine E, Overton L, Wang S, et al. Evolutionary dynamics of human rotaviruses: balancing reassortment with preferred genome constellations. PLoS Pathog. 2009;5:e1000634

23. Maunula L, Von Bonsdorff $\mathrm{CH}$. Frequent reassortments may explain the genetic heterogeneity of rotaviruses: analysis of Finnish rotavirus strains. J Virol. 2002;76:11793-800.

24. Matthijnssens J, Ciarlet M, McDonald SM, Attoui H, Banyai K, Brister JR, et al. Uniformity of rotavirus strain nomenclature proposed by the rotavirus classification Working group (RCWG). Arch Virol. 2011;156:1397-413.
25. Pantin-Jackwood MJ, Day JM, Jackwood MW, Spackman E. Enteric viruses detected by molecular methods in commercial chicken and turkey flocks in the United States between 2005 and 2006. Avian Dis. 2008;52:235-44.

26. Bezerra DA, da Silva RR, Kaiano JH, de Souza OD, Gabbay YB, Linhares AC, et al. Detection, epidemiology and characterization of VP6 and VP7 genes of group D rotavirus in broiler chickens. Avian Pathol. 2014;43:238-43.

27. Koo BS, Lee HR, Jeon EO, Han MS, Min KC, Lee SB, et al. Molecular survey of enteric viruses in commercial chicken farms in Korea with a history of enteritis. Poult Sci. 2013;92:2876-85.

28. Karim M, Rume F, Alam M, Ahmed M. Molecular epidemiologic study on avian rotavirus prevailing in Bangladesh. Bangl J Vet Med. 2007;5:43-8.

29. Oni OO, Owoade AA. Genetic evidence of rotavirus in chicken from two localities in southwestern Nigeria. Animal Res Int. 2010;7:1139-41.

30. WHO: Collecting, preserving and shipping specimens for the diagnosis of avian influenza a(H5N1) virus infection. Guide for field operations. 2006.

31. Kearse M, Moir R, Wilson A, Stones-Havas S, Cheung M, Sturrock S, et al. Geneious basic: an integrated and extendable desktop software platform for the organization and analysis of sequence data. Bioinformatics. 2012:28:1647-9.

32. Maes P, Matthijnssens J, Rahman M, Van Ranst M. RotaC: a web-based tool for the complete genome classification of group a rotaviruses. BMC Microbiol. 2009:9:238.

33. Castresana J. Selection of conserved blocks from multiple alignments for their use in phylogenetic analysis. Mol Biol Evol. 2000;17:540-52.

34. Talavera G, Castresana J. Improvement of phylogenies after removing divergent and ambiguously aligned blocks from protein sequence alignments. Syst Biol. 2007;56:564-77.

35. Gouy M, Guindon S, Gascuel O. SeaView version 4: a multiplatform graphical user interface for sequence alignment and phylogenetic tree building. Mol Biol Evol. 2010:27:221-4.

36. Darriba D, Taboada GL, Doallo R, Posada D. jModelTest 2: more models, new heuristics and parallel computing. Nat Methods. 2012;9:772.

37. Pauly M, Akoua-Koffi C, Buchwald N, Schubert G, Weiss S, Couacy-Hymann E, Anoh AE, Mossoun A, Calvignac-Spencer S, Leendertz SA, et al. Adenovirus in Rural Cote D'Ivoire: High Diversity and Cross-Species Detection. Ecohealth. 2015;12(3):441-52. doi:10.1007/s10393-015-1032-5. Epub 2015 May 20.

38. R Development Core Team. R: a language and environment for statistical computing. Vienna: Computing RFfS ed; 2008.

39. aod: Analysis of Overdispersed Data. http://cran.r-project.org/package=aod. Accessed 10 Apr 2012

40. Eddelbuettel D, François R. Rcpp: seamless R and C++ integration. J Stat Softw. 2011:40:1-18.

41. Ducatez MF, Martin AM, Owoade AA, Olatoye IO, Alkali BR, Maikano I, et al. Characterization of a new genotype and serotype of infectious bronchitis virus in western Africa. J Gen Virol. 2009;90:2679-85.

42. Snoeck CJ, Owoade AA, Couacy-Hymann E, Alkali BR, Okwen MP, Adeyanju AT, et al. High genetic diversity of Newcastle disease virus in poultry in west and Central Africa: cocirculation of genotype XIV and newly defined genotypes XVII and XVIII. J Clin Microbiol. 2013;51:2250-60.

43. Monne I, Meseko C, Joannis T, Shittu I, Ahmed M, Tassoni L, et al. Highly pathogenic avian influenza a(H5N1) virus in poultry, Nigeria, 2015. Emerg Infect Dis. 2015;21:1275-7.

44. Brüssow H, Nakagomi $\mathrm{O}$, Gerna G, Eichhorn W. Isolation of an avianlike group a rotavirus from a calf with diarrhea. J Clin Microbiol. 1992;30:67-73.

45. Brüssow H, Nakagomi O, Minamoto N, Eichhorn W. Rotavirus 993/83, isolated from calf faeces, closely resembles an avian rotavirus. J Gen Virol. 1992;73(Pt 7):1873-5.

46. Rohwedder A, Schutz Kl, Minamoto N, Brussow H. Sequence analysis of pigeon, turkey, and chicken rotavirus VP8* identifies rotavirus 993/83, isolated from calf feces, as a pigeon rotavirus. Virology. 1995:210:231-5.

47. Ito H, Minamoto N, Hiraga S, Sugiyama M. Sequence analysis of the VP6 gene in group a turkey and chicken rotaviruses. Virus Res. 1997;47:79-83.

48. Lin SL, Tian P. Detailed computational analysis of a comprehensive set of group a rotavirus NSP4 proteins. Virus Genes. 2003;26:271-82.

49. Trojnar $E$, Otto $P$, Johne R. The first complete genome sequence of a chicken group a rotavirus indicates independent evolution of mammalian and avian strains. Virology. 2009;386:325-33.

50. Johne R, Reetz J, Kaufer BB, Trojnar E. Generation of an avian-mammalian rotavirus Reassortant by using a helper virus-dependent reverse genetics system. J Virol. 2016;90:1439-43. 